\title{
Las nuevas formas de concertación política en América Latina*
}

América Latina es quizás la región del mundo que históricamente ha cifrado mayores esperanzas en la cooperación e integración regional. Ya a comienzos del siglo pasado, cuando por ejemplo la única integración que se concebía en Europa era aquella que se imponía por la fuerza de las armas y bajo un esquema imperial, los dirigentes políticos de las nuevas naciones latinoamericanas buscaban y proponían fórmulas y mecanismos para forjar la unidad de las antiguas posesiones españolas. En una forma u otra, esta búsqueda se ha mantenido hasta la actualidad, expresándose, como lo veremos más adelante, en distintos modelos que, cual más cual menos, parecen conservar su vigencia entre aquellos que siguen adhiriendo a los ideales regionales.

La persistencia de este ideal de unidad está, como sabemos, en abierto contraste con la realidad de las relaciones entre los mismos pafses latinoamericanos. Las periódicas conferencias celebradas entre distintos países de la región para construir la unidad continental no lograron impedir una sucesión de conflictos y tensiones que parecía reproducir los esquemas de equilibrio de poder vigentes en la Europa del siglo pasado, esquemas que se han perpetuado en las visiones geopolíticas de múltiples sectores militares y civiles de la América Latina contemporánea. Fue así como surgieron en el siglo pasado las guerras entre Brasil y las Provincias Unidas del Río de la Plata; Colombia y Perú; Chile, Argentina y la Confederación Peruano-Boliviana; la "Guerra Grande" en la región del Plata; la guerra de la Triple Alianza; la guerra del Pacífico; y una cadena interminable de enfrentamientos, intervenciones y tensiones históricas que sería largo enumerar. Durante este siglo, ni el establecimiento de un vasto sistema interamericano dotado de una compleja red de

*Trabajo preparado para el Proyecto "América Latina: hacia nuevas formas de vinculación internacional", coordinado por el Instituto de Estudios Internacionales de la Universidad de Chile, bajo Ios auspicios de la Corporación de Estudios Internacionales y la Fundación Interamericana. Una primera versión de este trabajo fue presentada en un seminario de discusión del Proyecto, celebrado en Arica, Chile, entre el I8 y el 22 de julio de 1984. El autor agradece los comentarios recibidos en esa oportunidad, especialmente del profesor Carlos Rico. 
organismos e instrumentos destinados a preservar la seguridad de la región y a resolver en forma pacífica las controversias entre sus miembros, ni el surgimiento posterior de esquemas y procesos de integración regionales y subregionales relativamente avanzados, han logrado evitar la subsistencia de viejos conflictos y la aparición de nuevas tensiones en la región. Por el contrario, conflictos y diferendos, generalmente de naturaleza territorial, siguieron marcando las relaciones entre países como Perú y Colombia, Bolivia y Paraguay, Perú y Ecuador, El Salvador y Honduras, Colombia y Venezuela, Chile y Argentina, Ghile y Bolivia, Venezuela y Guyana, Nicaragua y Honduras, etc.

En forma paralela a los grandes proyectos formales y omnicomprensivos de raíces bolivarianas o los esquemas más modernos y funcionales de integración económica regional, los países de América Latina han recurrido también en ocasiones a formas de concertación política de alcance más limitado, tanto en lo que concierne a sus objetivos como al número de países involucrados, que nuevamente parecen cobrar vigencia en la actualidad. Se trata de esfuerzos más puntuales, pragmáticos y flexibles, pero que encierran un gran potencial para la regulación de conflictos y problemas particularmente complejos y delicados. El desarrollo de estos mecanismos de orden político no sólo puede conducir a un nuevo enfoque para enfrentar las relaciones regionales sino que, eventualmente, podría reducir la presencia de actores e intereses extrarregionales en América Latina y así aumentar la autonomía de la región en sus relaciones con el resto del sistema internacional.

La concertación política surge en realidad como una nueva tendencia en la cooperación regional que, sin reemplazar necesariamente a los modelos anteriores, puede llegar a complementarlos y perfeccionarlos. En este trabajo intentaremos aproximarnos a este fenómeno más bien reciente, describiendo algunos casos concretos, especificando sus rasgos generales y evaluando su potencial. Para identificar mejor esta todavía incipiente tendencia, iniciaremos este análisis con una breve reseña de las vertientes más tradicionales en el campo de la cooperación regional intergubernamental.

\section{MODELOS Y TENDENGLAS HISTÓRTCAS DE LA COOPERACIÓN REgTONAL en AMÉriga llatina.}

\section{El modelo bolivariano omnicomprensivo}

Como lo señala Francisco Orrego Vicuña ${ }^{1}$, este modelo se identificó con las etapas formativas e iniciales de los estados latinoameri-

${ }^{3}$ Francisco Orrego Vicuña, "Sistema internacional, democracia y pluralismos: incidencias en la coordinación regional de políticas exteriores", publicado en Heraldo Muñoz y Joseph Tulchin (comps.), Entre la Autonomia y la Subordina- 
canos, una vez que éstos accedieron a la vida independiente. Alentaclos por el espíritu más regional que nacional asumido por la lucha por la independencia y movidos por un idealismo muy propio de toda gesta emancipadora, algunos grupos dirigentes de los nuevos países propiciaron proyectos particularmente avanzados y profundos de unificación regional, generalmente en la forma de federaciones, confederaciones y alianzas permanentes. Esta orientación inicial se hizo patente en algunos de los primeros vínculos entablados entre los estados de América Hispana y, sobre todo, en los congresos regionales celebrados durante el siglo pasado, a partir del histórico y frustrado Gongreso de Panamá de 1826. Aunque los proyectos presentados y debatidos en estas reuniones variaron considerablemente en el tiempo ${ }^{2}$, se trataba de promover la fusión política de la región mediante una aproximación gradual y formal, que contemplaba pactos defensivos y la adopción de principios generales e instrumentos específicos que consagraban la solidaridad e interdependencia política de las naciones hispanoamericanas.

Pese a las condiciones relativamente favorables que se presentaban en América Latina para la realización de algunos de estos proyectos, ellos fracasaron uno tras otro, estrellándose contra poderosas fuerzas centrífugas que, de hecho, impidieron la formación de un sistema regional hispanoamericano ${ }^{3}$. No fueron ajenas a este fracaso Ia misma pretensión omnicomprensiva de los proyectos, las solemnidades de que estaban revestidos y una creciente tendencia a esconder las realidades regionales bajo una retórica falsa y meramente formal.

Aún ast, algunos círculos de la región han seguido sintiendo un especial atractivo por los grandes proyectos de unidad, que no sólo se explica por la natural admiración que despierta la experiencia del proceso emancipador, sino que también por la fuerza de la tradición positivista del siglo xrx, que en ocasiones ha llevado a la creencia de que basta firmar un proyecto, pacto o tratado internacional para convertirlo en realidad. En sí, esta tendencia hacia la utopía parece natural y hasta saludable, pero da la impresión de que ella llevó a desestimar un extenso campo de acción de dimensiones mucho más modestas, que estaba representado por sectores especifi-

ción. Politica exterior de los paises latinoamericanos, Vol. In (Buenos Aires: Grupo Editor Latinoamericano, 1984) p. 466 y ss.

Véase sobre este tema Raymundo Barros Charlín, Consideraciones sobre la integración latinoamericana en el siglo XIx, con particular referencia a la politica de Chile (Santiago: Instituto de Estudios Internacionales de la Universidad de Chile, Serie de Publicaciones Especiales No 8, 1975).

3Hemos desarrollado este punto en Alberto van Klaveren, "Los antecedentes históricos del Sistema Interamericano", publicado en Rodrigo Díaz Albónico (ed.), Antecedentes, balance y perspectivas del Sistema Interamericano (Santiago: Ed. Universitaria, 1977), pp. 18-55. 
cos, afinidades limitadas, intereses compartidos y situaciones de hecho que podían dar pie a una cooperación regional más limitada pero por lo mismo más posible y promisoria.

\section{Los modelos de equilibrio de poder}

La frustración de Ios grandes proyectos unitarios no fue obstáculo para el desarrollo de diversos esquemas de alianzas defensivas y ofensivas durante el siglo xIx, que tendían a reproducir los sistemas de equilibrio de poder vigentes en Europa en esa misma época y que han ejercido considerable influencia en algunas perspectivas de política del poder contemporáneas en la región. Se trataba en este caso de mecanismos mucho más informales y flexibles centrados en percepciones de intereses nacionales de los distintos países; pero que, de hecho, contenían más elementos de conflicto que de cooperación regional. La interacción de estos mecanismos y esquemas lievó a un sistema regional relativamente inestable, marcado por diversos conflictos y guerras y una secuela de rivalidades y tensiones que persistieron durante este siglot.

\section{El modelo panamericano}

El creciente interés demostrado por los Estados Unidos hacia sus vecinos del Sur, en el que influyeron consideraciones económicas, políticas y de seguridad, unido a las grandes expectativas que cifraron muchos países latinoamericanos en el pujante país del Norte, llevaron al establecimiento de un sistema interamericano de cooperación que se fue institucionalizando mediante un proceso gradual y progresivo, que incluyó mecanismos formales, tratados y acuerdos $y$, con el tiempo, una red de organismos que subsisten hasta la actualidad.

Como cabía esperar de un esquema que incorporaba a países tan dispares y con intereses tan diferentes y, en varios aspectos, contradictorios, el sistema interamericano reprodujo en su interior la misma asimetría de sus integrantes, transformándose en un sistema de cooperación regional marcado por la influencia hegemónica de los Estados Unidos. Obviamente, esta influencia ha experimentado variaciones desde la época de las políticas del big stick y de la "diplomacia deì dólar", hasta el período actual de relativa declinación norteamericana en algunos campos específicos, pero no hasta el punto que pueda concebirse una revalorización de este sistema de cooperación regional que, por lo demás, en la mayoría de las ocasiones ha sido percibido por Washington como una instancia auxiliar y más bien secundaria dentro de su política exterior global. En consecuencia, ni los mismos Estados Unidos ni los países latinoameri-

"Véase sobre este punto Orrego, op. cit., pp. 469-471. 
canos parecen dispuestos a asignar un lugar significativo a este sistema en materia de cooperación política regional. Más bien, la principal función que puede llegar a desempeñar la oEA es la de servir como un foro o lugar de encuentro y debate entre un bloque relativamente heterogéneo de países que comparte una misma realidad económica y política internacional, y una gran potencia con la cual existe un alto nivel de interacciones, signadas tanto por el conflicto como por la cooperación.

\section{Los modelos integracionistas}

Factores tales como la urgente necesidad de replantear todo el tema de la cooperación regional en América Latina, el surgimiento de una nueva conciencia sobre el papel y las posibilidades de la región en el sistema internacional, que fue estimulada por los análisis de Ia cEPAL, la adopción de estrategias económicas desarrollistas, y la exitosa experiencia inicial de la integración europea, llevaron al diseño de diversos modelos de integración económica en la región, dentro de lo que constituyó y todavía constituye una de las tendencias más promisorias en este campo.

La oposición inicial entre dos visiones diferentes de la integración -una "desarrollista" que la vinculaba estrechamente a una nueva estrategia de desarrollo global y otra más "comercialista" que tendía a reducirla a la promoción y la facilitación del comercio regional- se resolvió inicialmente en favor de esta segunda alternativa, como la demostró la firma del Tratado de Montevideo en 1960, que dio origen a la Asociación Latinoamericana de Libre Comercio (ALALC), hoy transformada en la Asociación Latinoamericana de Integración (ALADI). Sin embargo, la insuficiencia intrínseca de este esquema confirmó la vigencia de las concepciones desarrollistas, que hasta cierto punto encontraron expresión en el Mercado Común Centroamericano y, luego en el Pacto Andino, que junto con pretender la liberación del comercio intrarregional, se propusieron. metas y objetivos de mayor alcance.

Concebidos como mecanismos de integración económica en una región caracterizada por la coexistencia, a menudo difícil, de distintos regímenes políticos y tendencias ideológicas, era poco lo que se podfa esperar de estas instituciones en el campo de la cooperación polftica externa. Esta posibilidad no sólo había sido omitida expresamente en los convenios constitutivos, sino que además fue considerada durante mucho tiempo como contraproducente y hasta incompatible con los fines de la integración económica regional. Implícitamente, se partía de la base que, de acuerdo a las concepciones teóricas neofuncionalistas, gradualmente el mismo proceso de integración iba a rebasar hacia el campo de la coordinación política por medio de un proceso lento y delicado que no debla ser 
forzado. Aunque algunos sectores estimaron que, dadas las condiciones existentes en América Latina, quizás debexía haberse invertido el proceso en el sentido de privilegiar primero la dimensión política para luego concentrarse en el campo propiamente económico, Ia tendencia dominante fue la de marginar los esfuerzos de cooperación política exterior de los mecanismos de integración económica, especialmente en el caso de Alalc, y canalizarlos a través de otras instituciones más "políticas" a nivel regional e internacional. Como veremos más adelante, el breve ensayo de "politización" del Pacto Andino emprendido en los años 1979 y 1980 representó una excepción a esta tendencia, que confirmó la regla general.

Aun cuando el sELA constituyó sin duda un enfoque novedoso y alternativo en materia de cooperación económica regional, sus funciones no se extendieron al campo más polf́tico de las relaciones exteriores de los países miembros. Más bien, se trataba de combinar una concepción más pragmática y flexible de los mecanismos de consulta, cooperación e integración de la región, con el papel que alcanzó a desempeñar cEcLA durante la segunda mitad de la década del 60 y comienzos de la siguiente como grupo de presión latinoamericano en los asuntos económicos internacionales que afectaban a la región.

\section{Las iniciativas de coordinación de las politicas externas}

En lo que toca a esfuerzos más limitados de cooperación en torno a uno o más objetivos específicos y puntuales, es claro que durante el periodo que se inicia con la postguerra América Latina exhibe una experiencia mucho más rica y sólida en el campo económico internacional que en el campo político. Esta experiencia se desarrolló a partir del marco teórico establecido por la CEPAL y el papel de liderazgo ejercido por distintos países y personalidades individuales en los variados foros y organismos internacionales en que comenzó a participar la región. Gabe mencionar en este sentido las posiciones adoptadas por los países latinoamericanos en el seno de los órganos de las Naciones Unidas, la constitución del Grupo Latinoamericano y su incorporación al Grupo de los 77 en la UNCTAD, el apoyo de los países de la región e iniciativas tales como el Nuevo Orden Económico Internacional, o la coordinación de las delegaciones latinoamericanas en foros especializados como la Conferencia de Derecho del Mar de las Naciones Unidas. A nivel regional, también se ha registrado una considerable concertación de los países latinoamericanos en la discusión de los asuntos económicos interamericanos y en la propuesta de instituciones tales como el Banco Interamericano de Desarrollo. Los avances que se lograron en este campo permitieron el establecimiento de la Comisión Especial de 
Goordinación Latinoamericana (CECLA) en la década de 1960, que desempeñó un papel de gran importancia en la coordinación y la toma de conciencia regional en materia de relaciones económicas internacionales y que, como ya se señaló, sirvió como antecedente para la constitución del SELA. Aun cuando los resultados efectivos de estos esfuerzos no han sido necesariamente satisfactorios para la región, por lo menos revelan una cierta voluntad de coordinación en el campo económico externo.

En el área política, en cambio, los países latinoamericanos no sólo han actuado divididos sino que además han sido incapaces de aprovechar algunas convergencias limitadas a nivel de determinados grupos de países. Como lo recuerda Olga Pellicer, frente a crisis como las de Guatemala en 1954, la cuestión cubana entre 1959 y 1964 en el sistema interamericano y la intervención en la República. Dominicana en 196.5, "Ios gobiernos Jatinoamericanos no respondieron de manera articulada, ni pusieron en evidencia su voluntad de actuar independientemente de Estados Unidos"5. De acuerdo con esta actitud reticente y cautelosa, las fosiciones independientes, disidentes o simplemente heterođoxas de ciertos países de la región tendieron a asumir un carácter más individual que colectivo, como lo ilustra el caso mexicano hasta la década del 70, o los casos de Brasíl, Argentina, Ghile o Perú durante ciertos períodos. Llama la atención, por ejemplo, que la coincidencia temporal que se produjo a comienzos de la década del 60 entre algunas posiciones más autónomas de política exterior de los tres países grandes de la región -Brasil, México y Argentina- no haya dado Iugar a una concertación limitada entre ellos, y que ésta tampoco se haya materializado entre los países que se opusieron a la intervención en la República Dominicana en 1965. Diversos factores explican esta incapacidad general de América Latina para concertarse en términos de sus posiciones externas en el campo político. Primero, la existencia de un sistema internacional rígido y estratificado, que no dejaba lugar para esfuerzos autonomistas de países medianos y pequeños, que además pertenecían a la periferia; segundo, y como consecuencia de lo anterior, el papel omnipresente desempeñado por los Estados Unidos en América Latina, que no sólo inhibía estos esfuerzos sino que despertaba fundados temores sobre las reacciones de Washington; tercero, Ia falta de constancia de las vocaciones autonomistas de algunos países de la región; cuarto, la escasa importancia que ocupaba América Latina en las políticas exteriores de los mismos países de la región; y, last but not least, el predominio de visiones rutinarias y excesivamente tradicionales $y$ formalistas en la elaboración de la política exterior.

${ }^{5}$ Olga Pellicer, "La concertación polftica en América Latina: la experiencia de Contadora", Revista Mexicana de Politica Exterior I (2), enero-marzo 1984, páginas $12-13$. 


\section{LOS NUEVOS ESFUERZOS DE CONCERTAGIÓN POLÍTICA}

El aumento en los márgenes de permisibilidad del sistema internacionale y un cambio global en las concepciones y estilos de política exterior prevalecientes en la región originaron una nueva y todavía incipiente tendencia hacia la cooperación política externa limitada a objetivos concretos y circunscritos. Esta tendencia no se restringió a determinados regimenes polfticos o alineamientos ideológicos: Es así como en una primera instancia se comenzó a percibir un acercamiento entre los nuevos autoritarismos que surgieron en la región durante las décadas del 60 y del 70, y que adoptaron lo que se conoció como diplomacias de seguridad nacionalt. Sin embargo, más allá de la cooperación que se gestó durante un tiempo entre algunos de estos regímenes, sobre todo en materias ideológicas y de control interno, su misma naturaleza atentó contra una coordinación mayor en el campo de la polftica exterior, ni siquiera frente a los factores externos que ellos percibían como hostiles (política de derechos humanos del gobierno de Carter, etc.). Ello, debido al predominio de visiones geopolíticas que ponían el acento en las rivalidades regionales y en los aspectos más conflictivos de las relaciones intralatinoamericanas, $y$ la adhesión, inicialmente absoluta, a modelos económicos que postulaban la apertura total de los países al extranjero y el libre juego de las fuerzas del mercado a nivel internacional, y que tendfa a descartar el valor de la cooperación regional.

En realidad, sólo hacia fines de la década del 70 comienzan a articularse iniciativas expresas de concertación política regional, entendida ésta como un esfuerzo más o menos sostenido de coopera. ción política entre varios países de la región con respecto a uno o más objetivos específicos, limitados en el tiempo y el espacio.

\section{El caso de Nicaragua}

La insurrección popular contra la dictadura de Somoza en Nicaragua dio lugar a una de las primeras experiencias de concertación política externa en la región. Ésta, en realidad, derivó casi naturalmente del interés que despertó el proceso nicaragüense en algunos países del área centroamericana y del Caribe y de la necesidad de

"EI concepto de permisibilidad ha sido desarrollado por Helio Jaguaribe en su libro Desarrollo Politico: sentido y condiciones (Buenos Aires: Paidós, 1972), Caps. Il y 12 y en su artículo "Autonomía periférica y hegemonfa céntrica", Estudios Internacionales 12 (46), abril-junio 1979, pp. 91-130.

Téase Alexandre S. C. Barros, "The Diplomacy of National Security: South American International Relations in a Defrosting World", en Ronald G. Hellman y H. Jon Rosenbaum (eds.), Latin America: The Search for a New International Role (New York: Sage, 1975), pp. I31-150. 
evitar que el conflicto interno tuviera efectos negativos para los países vecinos. Fue asf como en una primera instancia Costa Rica, Venezuela y Panamá empezaron a concertarse para evitar una acción de represalia de Somoza en contra de una Costa Rica indefensa, que no sólo estaba sirviendo de refugio para los guerrilleros sandinistas sino que además les permitía proveerse de armas. Esta cooperación informal se inició en los últimos meses de 1978, viéndose reforzada posteriormente por la participación de México. En esta etapa, no se trataba todavía de un esquema demasiado articulado, sino que más bien de una red de consultas y apoyos bilaterales centrados en puntos especificos. Así, mientras Venezuela y Panamá estaban comprometidos a asistir militarmente a Costa Rica en caso de un ataque somocista, Costa Rica y México se concentraron en el plano político, instando a otros países a romper relaciones con la dictadura nicaragüense. Como reflejo de este nuevo espíritu de concertación regional, en junio de 1979 los cinco países del Pacto Andino acordaron reconocer un "estado de beligerancia" en Nicaragua, en lo que constituyó un primer paso hacia el reconocimiento del Frente Sandinista de Liberación Nacional.

La expresión más clara de esta nueva tendencia se dio en el seno de la $\mathrm{OEA}$, con motivo de la reunión solicitada por el Gobierno norteamericano para.tratar el conflicto interno en Nicaragua. El objetivo de la convocatoria de Washington fue el de buscar algún mecanismo multilateral para intervenir en el conflicto y lograr una solución negociada que, básicamente, implicara el reemplazo de Somoza, un acuerdo entre sus antiguos partidarios, los sandinistas $y$ otros sectores, y la neutralización de la posibilidad de una "nueva Cuba". Sin embargo, el proyecto norteamericano fue frustrado por la oposición concertada de países como México, Panamá, 'Costa Rica, los miembros del Pacto Andino, Jamaica, Grenada y otros, unida a la reticencia de delegaciones como la brasileña, que tampoco favorecían una intervención en un conflicto interno cuyo desenlace ya era inminente. Finalmente, la OEA aprobó una moción que pedía la renuncia de Somoza, pero que condenaba cualquier intervención extranjera en el conflicto nicaragüense. Este ambiente de concertación limitada explica la rapidez con que los países latinoamericanos reconocieron al nuevo gobierno sandinista y el apoyo que la mayoría de ellos le prestó en su etapa inicial.

El esquema de cooperación política aplicado en este caso mantuvo siempre un carácter poco estructurado y flexible. Pese a que todos los países involucrados en él perseguían el mismo objetivo -el fin de la dictadura somocista- se pudo detectar una cierta variación en las medidas aplicadas por cada uno de ellos, desde el apoyo abierto de Panamá a los sandinistas hasta ocasionales intentos de negociación entre las fuerzas en pugna patrocinados por Venezuela, desde la ruptura de relaciones de México hasta el mantenimiento 
de las mismas en el caso colombiano, desde actitudes muy críticas hacia la posición de Washington hasta la realización de consultas periódicas con importantes personeros del Gobierno norteamericano.

\section{La búsqueda de la concertación politica en el Pacto Andino}

Una visión relativamente coincidente con respecto a varios problemas externos, una cierta afinidad política entre los países miembros, el mismo desarrollo del caso nicaragüense y esfuerzos desplegados por Perú y el Ecuador contribuyeron al establecimiento de un sistema de cooperación política en el seno del Pacto Andino. De acuerdo con este nuevo perfil político de la entidad, los Jefes de Estado de los países miembros se reunieron en ocho ocasiones entre septiembre de 1977 y diciembre de 1980, emitiendo documentos como el "Mandato de Cartagena" y el "Acta de Panamá" en 1979, y la "Declaración de los Presidentes de los países del Grupo Andino" y la "Carta de Riobamba" en 19808. Los objetivos que se perseguían era. la intensificación de las relaciones políticas entre los países miembros, la conformación de una unidad subregional capaz de desempeñarse como un actor político en el sistema internacional, la coordinación de las políticas exteriores, la promoción de la democracia y los derechos humanos y la solución pacífica de los conflictos $^{9}$. Estas nuevas funciones quedaron radicadas en el Consejo de Ministros de Relaciones Exteriores (Gonsejo Andino) y en el Parlamento Andino, además de las reuniones ocasionales que pudieren celebrar los Jefes de Estado de los países miembros.

Como ya se señaló más arriba, la primera expresión de este nuevo perfil político del Pacto Andino se dio en el caso nicaragüense, aun cuando se registró un matiz de diferencia entre la posición más entusiasta del Ecuador y de Perú y una posición más cautelosa de Venezuela y Colombia. Por otra parte, esta nueva dimensión política común se restringió a determinados asuntos externos, permitiendo que Ios países involucrados mantuvieran posiciones distintas frente a cuestiones como las relaciones con Guba, las políticas relativas al caso salvadoreño, los conflictos del Medio Oriente, etc.

Sin duda, el caso más interesante de concertación política andina fue el que afectó a uno de sus propios miembros: Bolivia. En efecto, los restantes integrantes del Grupo concertaron sus posiciones frente a las interrupciones del accidentado proceso de democratización boliviano ocurridas en noviembre de 1979 y julio de 1980.

8Para una buena descripción institucional del nuevo perfil político del Grupo Andino en que se citan estos documentos, véase Alberto Zelada Castedo, " $\mathrm{La}$ cooperación política en el Grupo Andino", Integración Latinoamericana 8 (83), septiembre 1983, pp. 30-48.

'Ibid., pp. 32-33. 
En el primer caso condenaron las violaciones a los derechos humanos del nuevo gobierno, el derramamiento de sangre causado por el golpe y su clara intencionalidad antidemocrática, mientras que en 1980 expresaron su desacuerdo con una nueva y grave interrupción del proceso democrático, haciendo un llamado para que se restableciera la plena vigencia de las instituciones democráticas y los derechos humanos ${ }^{10}$. Paralelamente a estos pronunciamientos crfticos, Ecuador rompió relaciones con el gobierno boliviano inmediatamente después del golpe de 1980, mientras que Colombia, Venezuela y Perú se abstuvieron de reconocer al nuevo régimen. Como consecuencia de esta nueva política, el gobierno militar boliviano se marginó de las reuniones del Grupo Andino, anunciando su intención de retirarse del esquema de integración subregional.

La firme actitud de los países del Pacto Andino contribuyó, sin duda, al aislamiento internacional del régimen de García Meza y a la posterior normalización democrática boliviana, haciendo que ésta adquiriera una alta dosis de inducción externa ${ }^{11}$. Ciertamente, esta política no fue exclusiva del Grupo Andino, sino que fue coincidente con actitudes similares de los países europeos, de la Comunidad Europea y, especialmente, del Gobierno norteamericano que, en su conjunto, configuraron un ambiente externo extremadamente hostil para el Gobierno Militar de La Paz.

Pese a estos comienzos auspiciosos, el nuevo esquema de cooperación política andina no logró consolidarse y fue abandonado poco después de la experiencia boliviana. Diversos factores explican este desenlace. En primer lugar, los dos casos en que se centró inicialmente representaron situaciones bien excepcionales, en que influyeron factores internos presentes en los mismos países, la naturaleza de los procesos nacionales y la posición del Gobierno norteamericano. Estos factores coincidentes no permitían la elaboración de una política de largo plazo en materia de concertación para la democratización. En segundo lugar, una vinculación tan estrecha entre un proyecto de integración subregional más bien estancado y frágil como el Pacto Andino con un sistema formal de cooperación política, envuelve considerables riesgos y dificultades, que muy luego se hicieron presentes en el caso andino ${ }^{12}$. Cabe señalar en este sentido que la misma fundamentación de este nuevo perfil político no 31023 .

${ }^{10}$ Keesing's Contemporary Archives, Vol. 27 1981, I4 agosto 1981, pp. 31022-

"Alberto van Klaveren, "Factores externos y regímenes democráticos en América Latina", Documento de Trabajo IcHeH, abril 1984, mimeo, p. 54.

${ }^{x}$ Estos riesgos no fueron ignorados por los auspiciadores de este nuevo papel político. Véase por ejemplo el artículo del ex Canciller peruano Carlos Garcfa Bedoya, figura central en estos esfuerzos, "La dimensión polftica del Grupo Andino", en su libro Política Exterior Peruana. Teoria y Práctica (Lima: Mosca Azul Editores, 198I), pp. 99-108. 
parecía muy convincente, desde el momento en que se asumía de que se trataba de una etapa superior a la que se estaba accediendo después de haberse "completado" las fases inferiores del proceso, supuesto que parece altamente discutible en el caso andino o de cualquier otro proceso de integración de América Latina. En tercer lugar, esta concertación política subregional tampoco estuvo exenta de costos reales para los países que la impulsaron. Así, en el caso del gobierno colombiano, el hecho de que los sandinistas que habían obtenido el respaldo de Bogotá reclamaran, apenas Ilegados al poder, el Archipiélago de San Andrés se transformó en una experiencia desalentadora y traumática que enfrió el entusiasmo colombiano por una política exterior más activa ${ }^{13}$ y que de paso lo expuso a una fuerte crítica interna. En el caso peruano, la política observada frente a los sucesos bolivianos fue percibida crecientemente como contradictoria con los intereses geopolíticos más permanentes de Lima, circunstancia que explica el que Perú haya terminado restableciendo relaciones con el régimen de García Meza. En Venezuela también se comenzó a revisar el perfil político asignado al Grupo Andino, en parte debido al deseo de Caracas de actuar individualmente en casos como el de Nicaragua, y en parte por los distintos intereses regionales de los venezolanos, que se orientan tanto hacia la subregión andina como hacia Centroamérica y el Caribe. Por último, el resurgimiento del conflicto peruano-ecuatoriamo en 1981 no sólo hizo imposible una concertación política externa a nivel andino sino que además puso en duda la capacidad de los propio miembros del Grupo para convivir pacíficamente.

En suma, aunque la breve experiencia de sooperación política emprendida dentro del marco andino creó grandes expectativas e incluso alcanzó algunos resultados concretos, su misma vinculación a un sistema formal e institucionalizado que había sido diseñado para otros fines lo hizo altamente vulnerable y frágil $y$, en definitiva, dejó al descubierto las importantes divergencias existentes entre los miembros del Grupo Andino. Una vez más, un excesivo énfasis en los mecanismos formales y las instituciones tradicionales, y el establecimiento de objetivos demasiado generales y ambiciosos habían contribuido a frustrar una mayor cooperación política entre un grupo significativo de países de la región.

\section{La guerra de las Malvinas}

El conflicto entre Argentina y Gran Bretaña proveyó una nueva oportunidad para la concertación política en América Latina, más

${ }^{13}$ Gerhard Drekonja y Fernando Cepeda, "Colombia", en Gerhard Drekonja y Juan G. Tokatlian (eds.) Teoria y Práctica de la Política Exterior Latinoamericana (Bogota; CEREC, 1983), p. 255. 
aún debido a que involucraba a un país de la región cuya reivindicación territorial se consideraba legítima y digna de apoyo, y un actor externo con un legado fuertemente colonialista.

En términos generales, los países de la región apoyaron con fuerza la posición argentina, ofreciendo ayuda económica e incluso, en algunos casos, militar a nivel bilateral, respaldando las reivindicaciones argentinas en las Naciones Unidas y en el Movimiento de Ios países No Alineados, y desplegando varias acciones a nivel diplomático. En la OEA, los pafses signatarios del Tratado Interamericano de Asistencia Recíproca (TIAR) aprobaron una resolución en que se apoyaba la reclamación territorial argentina, se instaba a Gran Bretaña a un cese inmediato de las hostilidades, se llamaba a ambos gobiernos a buscar una solución diplomática y se deploraba el embargo comercial impuesto por los países de la Gomunidad Económica Europea a la Argentina. La resolución contó con la abstención de cuatro países -Colombia, Chile, Estados Unidos y Trinidad Tobago-, y se concentró en el plano diplomático, sin referirse a una posible asistencia militar a la Argentina o la aplicación de sanciones comerciales o diplomáticas a Londres y sus aliados, medidas que tampoco fueron solicitadas por la delegación argentina ${ }^{14}$. Los países latinoamericanos también coordinaron su apoyo a Argentina en el marco del sELA donde, además de repudiar las medidas eco nómicas coercitivas adoptadas contra Argentina, establecieron un Comité de Acción de apoyo a ese país, integrado por 18 estados latinoamericanos, y comenzaron a formular una estrategia de seguridad e independencia económica regional. Este marco se tradujo en medidas especfficas de apoyo económico. El mismo espíritu se hizo evidente a nivel del Grupo Andino, pese a las reservas juridicas que había planteado Colombia respecto de la acción bélica argentina, y en los órganos económicos multilaterales de carácter global en que participaban los países de la región.

Sin embargo, detrás de esta actitud de apoyo general se escondian diversos matices y divergencias, que iban desde un apoyo muy amplio y ocasionales ofrecimientos militares de países como Venezuela, Perú, Cuba, Panamá y Nicaragua, pasando por posiciones más cautelosas y reservadas como las de México y Brasil, hasta actitudes más distantes y neutrales como las de Chile y Colombia. En parte, estas diferencias respondían a consideraciones de política territorial -varios de los países que se destacaron en su apoyo a Argentina tenían sus propias reclamaciones o problemas en este campo- o de percepciones de equilibrio de poder a nivel regional. Ėn parte, ellas derivaron de distintas posiciones jurídicas frente a la utilización de la fuerza por parte de Argentina para lograr una reivindicación territorial que todos los países de la región apoyaban,

1kLatin American Weekly Report, wR-82 - 17; 30 abril 1982, p. 2. 
y explicables aprensiones políticas frente a una aventura militar emprendida por un gobierno autoritario y represivo que prácticamente no tenía credibilidad ni prestigio a nivel internacional 15.

Estas consideraciones explican el carácter más bien limitado y simbólico de la concertación regional que se alcanzó respecto del conflicto. Por otra parte, ella no alteró mayormente la dura posición adoptada por el Gobierno británico tanto durante las acciones bélicas como con posterioridad a ellas, ni parece haber tenido un efecto disuasivo frente a los países que se aliaron con Londres, incluyendo en último término a los mismos Estados Unidos. De ahí que la solución definitiva del problema haya pasado a depender mucho más del debate político interno de Londres o de una eventual presión de Washington o de los países europeos, que de una acción latinoamericana. Esta realidad no sólo pareció confirmar la vulnerabilidad de América Latina frente a la acción de terceros actores en los planos militar, económico y político ${ }^{16}$, sino que nuevamente demostró la imposibilidad de responder en forma articulada. y coherente a desafíos externos cuando hay intereses y estilos diferentes en juego a nivel de los mismos parses de la región.

\section{El Grupo Gontadora}

La gravedad de la crisis centroamericana, su creciente internacionalización y una convergencia básica de intereses entre algunos países. de la región Ilevaron al establecimiento, a comienzos de 1983, en lá isla de Contadora (Panamá), de uno de los esquemas más novedosos e interesantes de concertación política en América Latina. Se trata, en primer lugar, de un esfuerzo exclusivamente regional, que vincula países que, teniendo un interés directo en todo cuanto sucede en la subregión centroamericana, ocupan una posición ventajosa y poseen recursos como para ejercer una influencia pacificadora y constructiva en el complejo conflicto. En segundo Iugar, tanto el estilo del Grupo como los mecanismos que ha empleado revelan una gran flexibilidad y originalidad, represențando un claro avance respecto de añejas prácticas a nivel del sistema interamericano o concepciones formalistas e institucionalistas que suelen primar en este tipo de esfuerzos. En tercer lugar, el Grupo reúne a países que, si bien comparten un interés básico y esencial en la pacificación de la región, mantienen visiones y vínculos diferentes con respecto a algunos aspectos y actores del conflicto, circunstancia que si bien

${ }^{10}$ éase sobre este punto, Heraldo Muñoz, "Efectos y lecciones del conflicto de las Malvinas", Estudios Internacionales 15 (60), octubre-diciembre 1982, páginas 499-512.

${ }^{10}$ Garlos J. Moneta, "El conflicto de las islas Malvinas: su papel en la polftica exterior argentina y en el contexto mundial", Estudios Internacionales 15 (60), octubre-diciembre 1982, especialmente pp. 401-405. 
en un sentido parece disminuir la efectividad del esquema, en otro lo hace más legítimo y menos teñido descle el punto de vista ideológico. Por cierto, estas ventajas no bastan para asegurar el éxito de la iniciativa dentro de un contexto regional tan turbulento y difícil como el centroamericano y una situación global igualmente adversa como la actual, pero al menos demuestran la existencia de enfoques y prácticas alternativas en materia de concertación polf́tica.

Las consideraciones básicas que han reunido a los cuatro miembros del Grupo Contadora -México, Venezuela, Colombia y Panamá- son variadas pero convergentes. En el caso de México, se trata de la necesidad de eliminar un foco de tensión internacional pró. ximo a sus fronteras, que lleva a un involucramiento futuro del país o requiera alterar una política tradicional de defensa de perfil más bien bajo17; el imperativo de crear un ambiente propicio para que se lleven a. cabo los profundos procesos de reformas económicas y sociales que, en la visión mexicana, son absolutamente necesarios para disminuir los conflictos en la región; la voluntad de desempeñar un papel más activo en un área contigua al país, que se hace evidente especialmente a partir de la administración del Presidente López Portillo; y el firme deseo de evitar que un conflicto que se percibe como básicamente local comience a responder a una lógica Este-Oeste, que se considera relativamente ajena a América Latina. Para Veriezuela, se trata de disminuir la tensión en una zona que hace ya bastante tiempo es estimada como prioritaria para su política exterior; de atenuar mediante un esquema multilateral el peligro de una posición demasiado expuesta en la zona, derivada del papel protagónico que se había asignado Caracas durante los dos últimos gobiernos; y, quizás, de tender a una posición que refleje más los intereses del Estado venezolano que de los sucesivos gobiernos de turno. En el caso de Colombia, se trata de bloquear la internacionalización de sus propios movimientos guerrilleros y llevar adelante un proceso casi simétrico de pacíficación interna y externa; neutralizar el conflicto territorial con Nicaragua; y buscar un perfil más activo y constructivo para una política exterior que hasta entonces había sido pasiva y, en más de un sentido, hasta anacrónica. Finalmente, para Panamá se trata de impedir que el conflicto crezca y llegue a involucrar al país, partiendo con la utilización de las bases norteamericanas en acciones dirigidas a Centroamérica; neutralizar el peligro de una intervención norteamericana que podría expandirse fácilmente hacia el Canal, atendido el valor estratégico que le asigna Washington y el descontento de muchos sec-

${ }^{17}$ Este punto ha sido desarrollado por Mario Ojeda, "La política exterior de México: objetivos, principios e instrumentos", Revista Mexicana de Politica Exterior 1 (2), enero-marzo 1984, p. 8 y ss. 
tores de la derecha norteamericana respecto de su traspaso al Estado panameño; y propiciar un papel más activo del país en materia de relaciones internacionales, que se explica a partir de la estrategia que desarrolló para recuperar el Canal. La convergencia de todos estos intereses y motivaciones explica el que se hayan pasado por alto las diferentes posiciones que han mantenido México y Venezuela con respecto al problema interno de El Salvador o la experiencia sandinista en Nicaragua, así como otras percepciones igualmente distintas de los restantes países.

La acción del Grupo de Contadora está dirigida fundamentalmente a la pacificación de la región centroamericana. El énfasis está puesto en los aspectos externos, aunque no se han omitido algunas referencias a principios de organización política interna, en la medida en que incidan eń aquéllos y se mantengan dentro de un plano genérico y más bien abstracto. En cuanto a los Estados Unidos, sin duda el actor externo principal en la zona, el Grupo no se percibe a sí mismo como un instrumento de lucha contra la gran potencia ${ }^{18}$, aunque ciertamente pretende atenuar en alguna medida. el papel que tradicionalmente ésta ha desempeñado ahí.

Los objetivos específicos del Grupo Contadora son bastante claros y directos, aunque no por ello menos difíciles de alcanzar. Ellos incluyen la promoción de la distensión y la solución de los conflictos en el área; la detención de la carrera armamentista y el inicio de negociaciones para el control y reducción de los armamentos existentes; la proscripción de la instalación de bases extranjeras u otras formas de injerencia militar foránea en el área; la celebración de acuerdos para terminar con la presencia de asesores militares extranjeros en los países centroamericanos; el establecimiento de mecanismos de control para el tráfico de armas en la zona; la adopción de medidas que impidan el uso del territorio u otras formas de apoyo más activo de un país o movimientos, fuerzas o grupos que pretenden desestabilizar a otro gobierno centroamericano; y otras medidas similares. En el plano interno, el Grupo de Contadora ha puesto énfasis en dos categorías de principios generales: por una parte, el fortalecimiento de las instituciones democráticas, la adopción de mecanismos de participación política plena, la observancia de los derechos humanos, y la consagración del pluralismo en sus diversas manifestaciones; $y$, por la otra, la promoción de proyectos de desarrollo y justicia social, que se estiman indispensables para alcanzar los objetivos anteriores ${ }^{19}$. Mediante estos objeti-

${ }^{18}$ Olga Pellicer, op. cit., p. 14.

${ }^{19}$ Véase la recopilación de documentos del Grupo de Contadora incluida en Capitulos del SELA, 4, abril 1984, pp. 43-58; en especial la "Declaración de Contadora", del 9 de enero de 1983, la "Declaración de Cancún sobre la Paz en Centroamérica", del 17 de julio de 1983, el "Documento de Objetivos del Grupo de Gontadora", del 9 de septiembre de 1983, y las "Normas para la Ejecu- 
vos específicos sé pretende desvincular la compleja situación externa $e$ interna de la región del conflicto Este-Oeste. Es obvio que esta meta de largo plazo exige también un diálogo directo con los Estados Unidos y con Cuba, el que hasta ahora ha sido conducido principalmente por México. Más allá de estas medidas específicas, el Grupo de Contadora no pretende ofrecer soluciones concretas a Ios problemas internos de países como EI Salvador, Nicaragua o Guatemala, ni se pronuncia sobre la legitimidad y representatividad de sus gobiernos. A nivel individual, los miembros del Grupo podrán patrocinar medidas de mayor o menor apoyo en cada caso concreto -como de hecho ha sucedido entre México y el gobierno sandinista de Nicaragua o, en menor medida, entre Venezuela y el gobiemo salvadoreño- pero a nivel colectivo, el Grupo Gontadora sólo se propone contribuir al establecimiento de un marco general que permita, más que la solución de los conflictos, su regulación por medios específicos.

Desde el punto de vista institucional, el Grupo ha adoptado una estructura flexible y orientada hacia el consenso entre sus integrantes. En enero de 1984 se establecieron tres Comisiones de Trabajo sobre asuntos de seguridad, asuntos políticos, y asuntos económicos y sociales. Las decisiones han sido tomadas en sucesivas reuniones, generalmente de carácter informal, a nivel de los Ministros de Relaciones Exteriores y, eventualmente, de Ios mismos Jefes de Estado, que además han cumplido con un intenso programa de giras y visitas a los otros países miembros y a la región centroamericana.

No cabe duda de que la iniciativa de Contadora ha tenido una excelente acogida a nivel internacional, como Io demuestran la Resolución 530 del Consejo de Seguridad de las Naciones Unidas, la Resolución 30/10 adoptada durante el trigesimoctavo período de sesiones de la Asamblea General, diversos pronunciamientos del Movimiento de los Países No-Alineados, acuerdos de Ia OEA, declaraciones de organizaciones internacionales no gubernamentales como las Internacionales Socialista, Demócrata Cristiana y Liberal, y una infinidad de comunicados $y$ declaraciones a nivel de gobiernos como los de Argentina, Ecuador, Cuba, Brasil, Perú, España, Francia, Alemania Occidental, Suecia, Holanda, Yugoslavia, Egipto, Canadá, la República Popular de China, Estados Unidos, la Unión Soviética, India, etc. Igualmente se encuentra una referencia al Grupo en el Informe de la Comisión Nacional Bipartita sobre Centroamérica establecida en los Estados Unidos ${ }^{20}$, también Ilamado Informe Kissinger, y en prácticamente todos los informes privados emitidos

ción de los Objetivos" propuestas a los cinco pafses centroamericanos y adoptadas el 8 de enero de 1984 en Panamá.

${ }^{20}$ Véase Comisión Kissinger. Informe de la Comision Nacional Bipartita sobre Centroamérica México: Ed. Diana, 1984), pp. 158-160, en que se apoya la labor del Grupo Contadora, sin dejar de señalar algunas dudas sobre su eficacia. 
sobre el tema en los Estados Unidos. Sin embargo, tras este apoyo casi unánime se esconde una buena dosis de pesimismo, en especial a nivel del gobierno norteamericano $y$, probablemente, de Moscú, que por razones obvias no parecen estar interesados en desvincular el tema centroamericano del conflicto Este-Oeste. En el caso de Washington, es claro que pese a las reiteradas expresiones de adhesión a Contadora, se sigue prefiriendo un trato directo y estrictamente bilateral con los países involucrados en el conflicto, como única forma para mantener un relativo control de la situación mediante un sistema de presiones y concesiones, relativo porque en último término éste depende de las condiciones objetivas existentes en la región. Por su parte, los países centroamericanos han aceptado formalmente los principios contenidos en el "Documento de Objetivos", también conocido como el "Documento de los 21 puntos", y sus respectivas "Normas de Ejecución", pero sería ingenuo pensar que esa aceptación deriva de una voluntad real de cumplir con cada uno de estos principios. Después de todo, Honduras ha seguido involucrándose en el conflicto centroamericano mediante una estrategia casi suicida de asociación con los Estados Unidos, y Nicaragua llevó en octubre de 1983 su conflicto al Consejo de Seguridad de las Naciones Unidas, lo que no parece conducente a evitar una mayor internacionalización del problema.

Ciertamente, el cuadro anterior exige mantener una gran cautela en la evaluación de las posibilidades de éxito del Grupo de Contadora. La situación centroamericana, tanto en sus aspectos internos como externos, no permite ser demasiado optimista en este sentido. Sin embargo, estas prevenciones no impiden calificar desde ya a esta experiencia como uno de Ios esquemas más novedosos y positivos de cooperación política regional, especialmente en cuanto a proceso de aprendizaje y testimonio de la voluntad polftica de un grupo de países latinoamericanos de buscar soluciones propias y constructivas para un conflicto cada vez más inquietante y agudo. Con todas sus debilidades, este esquema ya ha contribuido a alejar el espectro de una guerra regional por un lapso de dos años, logro que parece notable dentro de un contexto tan complejo y explosivo como el centroamericano.

\section{DIMENSIONES, REQUUSITOS $X$ POTENCIAL DE LA CONCERTAGIÓN POLf́TICA}

\section{Dimensiones relevantes}

Tentativamente, las experiencias de concertación política regional pueden analizarse a partir de dos dimensiones básicas: nivel de institucionalización y alcance.

La primera de estas dimensiones se refiere a la existencia de tra- 
tados, mecanismos, estructuras organizativas y un patrón preestablecido y formal de funcionamiento. Desde este punto de vista, un esquema de cooperación podrá ser más o menos estructurado, más - menos formal. A su vez, en el caso de los modelos altamente institucionalizados, también se puede hacer una distinción entre aquellos simplemente intergubernamentales y aquellos que se acercan a nociones supranacionales $y$, en último término, federales.

La segunda dimensión dice relación con los contenidos, objetivos y sectores específicos que cubre la cooperación. Desde esta perspectiva, una experiencia de concertación puede ser limitada o sectorial, cuando cubre algunos aspectos, o inclusive, cuando tiene una orientación más amplia y general. En el campo económico, según lo han analizado los teóricos de la integración, se pueden concebir esquemas dirigidos al comercio, desarrollo, transporte, finanzas, tratamiento a terceros actores, etc., o bien hacia todos estos objetivos a la vez. Asimismo, en el campo político la cooperación se puede referir a determinados asuntos, a una coordinación general de todos los temas específicamente políticos, o a los temas de defensa y seguridad. También es posible concebir esta distinción en términos geográficos, en el sentido de que la cooperación puede implicar sólo una región o un universo geográfico muy amplio. Las combinaciones son por lo tanto múltiples y variadas. En el caso actual de la Comunidad Europea, por ejemplo, se da un esquema de cooperación política bastante avanzado que, sin embargo, hasta ahora no ha cubierto prioritariamente los aspectos de seguridad, que la mayoría de sus miembros sigue tratando a nivel de la otan (aunque esto podría variar en el futuro).

Aun cuando ambas dimensiones tienden más a continuos que a clasificaciones dicotómicas, para los fines del análisis se puede configurar el siguiente cuadro en materia de modelos actuales de cooperación polf́tica:

\section{INSTITUGIONALIZACION}

Baja

Alta

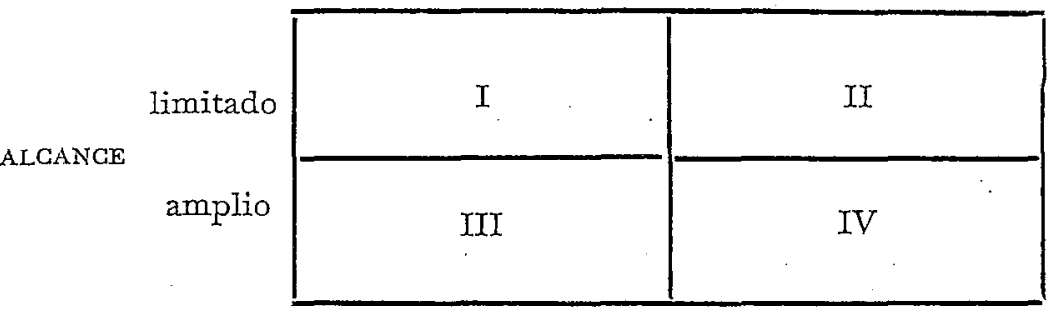

En el caso de América Latina, el modelo I, de baja instituciona- 
lización y alcance limitado, podría corresponder al Grupo de Gontadora. El modelo II, de alta institucionalización y alcance limitado podría incluir el caso del Grupo Andino en su dimensión politica, que si bien tenía objetivos más amplios desde el momento en que pretendía coordinar las políticas exteriores generales de los países miembros, en la práctica se concentró en asuntos tales como Ios procesos de democratización en algunos países de la región. El modelo III, de baja institucionalización y alcances amplios, podría agrupar a los esquemas de alianzas informales y ejes polfticos e ideológicos que ocasionalmente han existido en la región (Guatemala-Honduras-El Salvador, Guba-Grenada-Nicaragua, etc.) y que suelen tener una naturaleza más bien transitoria. Finalmente, el modelo IV, de alta institucionalización y alcance amplio, correspondería al proyecto té́rico y original -aunque ciertamente no a la realidad-del sistema interamericano o a los recurrentes llamados que se hacen en América Latina para formar una organización de estados latinoamericanos (OELA), el último de los cuales se formuló, aparentemente sin mucha convicción, con motivo de la guerra de las Malvinas.

Estos modelos tienen un carácter teórico $y$, en general, tienden a aparecer confundidos en la realidad. Así, se puede pensar en un esquema de integración sectorial económica con objetivos supranacionales - caso del Pacto Andino- combinada con un esquema de cooperación política limitada en que participan sólo algunos de sus miembros. Pero lo que interesa destacar es que, desde el punto de vista analfitico, parecen vislumbrarse modelos y estilos distintos de cooperación política susceptibles de evaluaciones igualmente diferentes. En este trabajo nos hemos concentrado en el primer modelo debido a la convicción de que las condiciones existentes en la región no parecen estar maduras para esfuerzos más profundos en el campo específico de la cooperación política y que, en cambio, una serie sucesiva de ensayos con este modelo inicial podría abrir el camino para la introducción de los otros esquemas más exigentes.

\section{Condiciones externas e internas para la concertación política}

Es claro que un incremento de la cooperación entre los países latinoamericanos en este plano sólo parece posible dentro de un cierto pluralismo político internacional y un grado relativo de permisibilidad ${ }^{21}$. Los cambios que se han venido registrando a nivel del sistema internacional global, que se han orientado hacia una mayor diversificación y fragmentación del poder, y el papel más autónomo que han comenzado a desempeñar varios países latinoamericanos, apuntan en esa dirección. Aunque también aquí parece hacer algu-

2Yéase sobre este punto Francisco Orrego Vicuña, op. cit., p. 465. 
nas prevenciones en el sentido de que si bien hay una cierta declinación de las superpotencias a nivel global, en América Latina este proceso es más dudoso, complejo y contradictorio ${ }^{22}$, se puede afirmar que la región goza de una mayor autonomfa relativa en sus acciones externas que hace dos o tres décadas atrás.

En el plano de las políticas exteriores de los mismos pafses latinoamericanos, la concertación polf́tica requiere de una orientación prioritaria, aunque de ningún modo exclusiva, hacia la misma región. Esta condición que parece tan obvia no se ha dado históricamente en todos los casos, especialmente con respecto a las potencias regionales. Así, durante mucho tiempo ni Brasil, ni México, ni Argentina le asignaron este lugar prioritario a América Latina en sus politicas exteriores, situación que hoy parece haberse alterado por una serie de circunstancias externas e internas. Por otra parte, también se requiere que el principio que anime esa orientación regional sea consensual y cooperativo, en el sentido de que esté libre de elementos de presión y de propósitos expansivos o de creación de áreas de influencia, lo que implica el abandono de visiones geopolíticas y excluyentes que en ocasiones pueden alcanzar gran popularidad en la región. Otro requisito fundamental a este nivel es un grado mínimo de autonomfa con respecto a potencias con intereses hegemónicos en la región, factor que ha sido y seguirá siendo clave en el caso del Grupo Contadora.

En materia de recursos, un esfuerzo sistemático de concertación polftica siempre requiere de infraestructuras mfnimas de apoyo a nivel nacional que permitan participar en largos y complejos procesos de negociación. En consideración a los intereses involucrados en estos procesos, parece conveniente no descansar exclusivamente en la diplomacia tradicional, sino que incorporar a técnicos, politicos y comunicadores que pueden aportar enfoques $y$ vinculaciones novedosas y diferentes $y$, además, servir de puente hacia la misma opinión pública de sus pafses. Aunque se trate de áreas y esfuerzos diferentes, la concertación política puede beneficiarse mucho de un esquema previo o simultáneo de cooperación económica. Es lo que ha sucedido por ejemplo en el caso centroamericano, donde México y Venezuela ya estaban prestando una ayuda muy valiosa mediante el Programa de Cooperación Energética para Países de Centroamérica y el Caribe, establecido en 1980, que contempla el abastecimiento de petróleo a estos países y la concesión de financiamiento preferencial hasta por el $3 \%$ de las facturas por este concepto, sin ataduras políticas de ninguna especie ${ }^{23}$. Dentro del mis-

mNos hemos referido a este tema en Alberto van Klaveren, "El Iugar de Estados Unidos en la polftica exterior latinoamericana", en Drekonja y Tokatlian (eds.), op. cit., pp. 119-141.

2Véase al respecto el artículo de Gabriel Rosenzweig, "La cooperación económica, de México con Centroamérica a partir de 1979. Perspectivas para los 
mo espíritu de combinar la cooperación política con la económica, se estableció a nivel del sELA en diciembre de 1983, el Comité de Acción de Apoyo al Desarrollo Económico y Social de Centroamérica (GADESCA) ${ }^{24}$, al cual adhirieron 18 países miembros. La relación existente entre los esfuerzos de concertación política y las capacidades diplomáticas y hasta cierto punto económicas de los países involucrados sugiere la utilidad de que participen en ellos algunas potencias regionales, también llamadas "intermedias" a nivel global25, o bien, un conjunto relativamente representativo de países medianos a nivel latinoamericano. Asimismo, el requisito de la orientación consensual tendrá mayor fuerza y credibilidad en la medida en que no se restrinja a sólo una potencia regional asociada con pafses menores, sino que a un conjunto más amplio de naciones.

Como es obvio, la cooperación política supone un esfuerzo de liderazgo $\mathrm{y}$, especialmente la voluntad de aumentar los márgenes de participación internacional y adoptar un comportamiento más activo, diferenciado y autónomo en el plano externo. En este sentido, parece conveniente buscar un punto intermedio entre una actitud pasiva y una posición demasiado protagónica tanto por parte de los passes como de las personalidades involucradas, que a la larga puede ser contraproducente. También hace falta una evaluación muy cuidadosa de los intereses presentes y de los costos y beneficios para cada país que participe en el esquema de cooperación, que evite la tentación de dejarse arrastrar por políticas de prestigio o de involucrarse en áreas y problemas que no son de interés prioritario o para los cuales no se dispone de la experiencia y recursos indispensables para desempeñar un papel positivo. No se trata, entonces, tan sólo de una cuestión de voluntad política, sino que también de una de oportunidad, necesidad real y capacidad.

\section{Potencial de las nuevas experiencias}

En una etapa todavía tan primaria de la concertación polftica en América Latina, ésta debe ser evaluada más como un proceso de aprendizaje que en cuanto a sus resultados concretos. Sería por cierto absurdo no asignar importancia a los logros específicos de un esquema como el del Grupo Contadora, pero aun si éstos no fueran $\tan$ espectaculares, la experiencia en sí podrfa representar

próximos años", en Olga Pellicer (eds.), La política exterior de México: desafios en los ochenta (México: Ensayos del crde, 1983), pp. 235-272.

${ }^{2}$ Los antecedentes de esta nueva iniciativa figuran en Capitulos del sELA No 4, abril 1984, pp. 3-42.

${ }^{25}$ Para un buen tratamiento teórico del tema de las potencias intermedias en América Latina, véase el artf́culo de Guadalupe González, "México", en la compilación de Drekonja y Tokatlian, op. cit., pP. 299-353. 
un avance muy positivo. Lo mismo puede afirmarse con respecto a otras iniciativas similares. Ello, debido a lo que significa la cooperación política en cuanto configuración de una visión articulada, diferenc:ada y propia de los problemas regionales; en cuanto búsqueda de un modelo alternativo; en cuanto afirmación de una cierta autonomía internacional en un mundo estratificado que, en muchos aspectos, sigue aferrado a una lógica bipolar; y, por último, en cuanto ejercicio de convergencia de intereses diversos y de desarrollo de nuevas capacidades de política exterior.

Tratándose de un proceso muy pragmático $v$ gradual, sería erróneo esperar resultados demasiado dramáticos de estas primeras experiencias. Más bien, hay una serie de mecanismos que podrian ensayarse para el futuro inmediato y que, pese a su carácter más bien modesto y reducido, encierran un importante potencial para la región. Estamos pensando, por ejemplo, en el desarrollo del principio de las consultas frecuentes e informales, que prescindan de las solemnidades que tradicionalmente se le han asignado a estas instancias en América Latina; en el establecimiento de lazos permanentes entre los funcionarios medios y superiores de las burocra. cias estatales, lo que parece esencial para mantener la continuidad de estas experiencias en un continente en que los cambios polfticos son frecuentes; en la participación complementarja de sectores ajenos a los servicios exteriores en estos esfuerzos; en la constitución de comités y grupos de trabajo informales centrados en objetivos especificos; en fin, en la existencia de procesos acumulativos y evoIutivos en distintos campos. Esta actividad básicamente intergubernamental se complementaría adecuadamente con procesos similares a nivel de los actores no estatales en la región, que también están comenzando a concertarse en forma limitada en torno a objetivos especificos tales como la cuestión de la democratización en América Latina, la defensa de los derechos humanos y otros temas igual. mente fundamentales y que deben ser materia de otro estudio.

Es importante subrayar el argumento de que la concertación poIftica no constituye una alternativa a la integración regional, ni en cuanto a su contenido, que tiende a ser diferente, ni en cuanto a sus efectos. Incluso, una experiencia positiva en este campo podría darle nueva fuerza a un proceso de integración que parece muy estancado en América Latina. En el caso de la Comunidad Europea, por ejemplo, no sólo se ha producido un fuerte contraste entre un proceso de integración que en varios aspectos está en crisis y un notable y quizás poco conocido avance de la cooperación política regional, sino que es posible que este último proceso logre revitalizar y renovar los esquemas clásicos de integración. Se establece, entonces, una relación complementaria en que ambos procesos se refuerzan mutuamente, pese a que tienden a responder a dinámicas distintas. 
Un último elemento que debe ser considerado al evaluar el potencial de la cooperación política intergubernamental se refiere a los apoyos externos que ésta requiere. Considerando la estructura del sistema internacional actual, es poco probable que América Latina pueda tener éxito en este campo sin la búsqueda de estos apoyos fuera de la región, tanto a nivel de las sociedades como de los mismos gobiernos. Hay coincidencias e intereses similares y convergentes susceptibles de ser aprovechados en este sentido, como por ejemplo, una común percepción de vulnerabilidad entre países europeos y de América Latina o la posición de algunos sectores internos norteamericanos. Se trata, en todo caso, de la búsqueda de apoyos y no de una participación activa de los actores extrarregionales en estos esfuerzos. De acuerdo a esta visión, la concertación política debiera considerarse como un proceso fundamentalmente latinoamericano. Precisamente esta circunstanciá contribuye a darle fuerza y valor. 